\title{
Environmental responses of jellyfish polyps as drivers of medusa populations off the coast of Namibia
}

\author{
L. Ziegler and M.J. Gibbons
}

\begin{abstract}
Jellyfish populations in the southeastern Atlantic off the coast of Namibia have increased subsequent to the decline of small pelagic fisheries at the end of the 1960s, although the environment there has also become warmer and the waters off Walvis Bay have become richer in zooplankton in recent years. Laboratory experiments were conducted with the scyphozoan jellyfish Chrysaora fulgida to investigate the effects of food density (o, 30, 70, 100 or 150 Artemia nauplii $200 \mathrm{ml}^{-1}$ ), feeding frequency (once daily or once every third day) and water temperature $\left(12,16\right.$ or $\left.20{ }^{\circ} \mathrm{C}\right)$ on the asexual reproduction, growth and development of polyps. The results of a generalised linear mixed-effects model reveal that all variables impacted asexual reproduction, with greater polyp production attained at higher food concentrations, increased feeding frequencies and increased temperatures. The most common mode of asexual reproduction was by lateral budding. These laboratory results suggest that polyps of $C$. fulgi a may have proliferated off Namibia in recent times, which would contribute to increased numbers of jellyfish there.
\end{abstract}

\section{Introduction}

Jellyfish populations off Namibia appear to have increased in size subsequent to the overfishing of small pelagic fishes there at the end of the 1960s (Venter 1988; Roux et al. 2013), though the jellyfish populations at present may be relatively stable (Flynn et al. 2012). In 2003, the biomass of jellyfish (i.e. Chrysaora fulgida [Reynaud, 1830] and Aequorea forskalea [Péron \& Lesueur, 1810]) in the northern Benguela Current ecosystem was estimated to exceed that of all commercial finfish (Lynam et al. 2006).

Increases in jellyfish populations have been noted in a number of ecosystems around the world (e.g. Brotz et al. 2012; Richardson et al. 2012), although whether these are sustained increases or simply increases associated with natural cycles is yet unclear (Condon et al. 2013; Gibbons and Richardson 2013). A number of anthropogenic drivers have been proposed to explain the recent increases in jellyfish abundance, such as overfishing, cultural eutrophication, alien introductions, the proliferation of hard substrata, and climate change (Purcell et al. 2007). In the Namibian situation, two of these may be important: overfishing and climate change. Roux et al. (2013) eloquently articulated the case for the former, and it is likely that overfishing created the initial 
'space' for jellyfish to move into (Bakun and Weeks 2006). Since 1980, however, the marine ecosystem off Namibia has become warmer (Salvanes et al. 2015), and there has been an increase in the abundance of copepods off Walvis Bay, with changes in size composition favouring smaller copepods (Verheye et al. 2016).

Scyphozoans (and many hydrozoans) have a metagenic life cycle, wherein there is an alternation between generations of free-swimming medusae and (generally) a benthic polyp phase. The medusae reproduce sexually and the fertilised eggs develop into planula larvae that (typically) settle onto a hard substrate, whereas the polyps reproduce asexually to produce ephyrae and new polyps. Though temperature (Hansson 1997; Widmer 2005) and food (Olesen et al. 1996) can influence the growth of ephyrae, and likely too adult medusae, how these variables may quantitatively affect planula production and the size of future medusa populations is unknown. However, in the case of benthic polyps it is clear that both temperature and food can influence polyp population sizes (Lucas et al. 2012) and, by likely extent, subsequent medusa populations. At least, both food supply and temperature have been implicated as causative factors leading to jellyfish blooms elsewhere in the world (Purcell et al. 2007).

Our understanding of the factors that influence the polyps of Namibian jellyfish, especially scyphozoans, is presently non-existent as none have ever been observed in situ. However, we recently managed to culture some polyps of Chrysaora fulgida in the laboratory, following the methods of Widmer (2008a), and we used these to investigate the effects of water temperature, food density and feeding frequency on polyp growth and development.

\section{Materials and methods}

Polyps of Chrysaora fulgida were derived from planulae collected in 2013 from the lagoon at Walvis Bay, Namibia. Polyps were plated on plastic Petri dishes and maintained in shallow, flow-through aquaria in the laboratory at the University of the Western Cape, South Africa, at a salinity of 35 (natural seawater). Ambient temperature was maintained at a constant $14{ }^{\circ} \mathrm{C}$, and animals were exposed to a $12 \mathrm{~h}$ dark:12 h light regime. Polyps were fed with newly hatched Artemia nauplii, ad libitum once weekly, and re-plated on an ad hoc basis, when necessary.

In 2015, a series of experiments were conducted to investigate the effects of feeding frequency (once daily or once every third day), water temperature $\left(12,16\right.$ or $20{ }^{\circ} \mathrm{C}$ ) and food density (at o, 30, 70, 100 or 150 newly hatched Artemia nauplii $200 \mathrm{ml}^{-1}$ ) on polyp growth and development, comprising 30 different treatments in total. Experiments were conducted over a 30-day period during September- October. Experimental polyps (8-17 tentacles, non-strobilating) were isolated from the main culture, plated on plastic Petri dishes (four per plate) and acclimated (in 350-ml glass beakers) to each experimental temperature for five days, without food, at a salinity of 35 and under a $12 \mathrm{~h}$ dark:12 $\mathrm{h}$ light regime. The glass beakers were suspended below the surface in aquaria wherein the water temperature was maintained at experimental levels using thermostat-controlled 
heaters or chillers. The seawater within each glass beaker was replaced daily and observations were made on individual polyps immediately prior to feeding. The observations included a count of the number of daughter polyps and the modes of reproduction, with the latter identified following the descriptions of Adler and Jarms (2009) and Schiariti et al. (2014).

Data on the numbers of polyps produced were analysed using a generalised linear mixedeffects model (GLMM; with log-link), with temperature, food density and feeding frequency as fixed effects, and tank number and polyp (per individual) as random effects. Daily population growth rate $(r)$ was calculated as:

$$
\text { Daily growth rate }(r)=\frac{N_{t}}{N_{t-1}}
$$

and

Standardised daily growth rate $(X)=\left[\frac{N_{t}}{N_{0}}\right]^{1 /\left(t_{t}-t_{0}\right)}$

where $N_{t}, N_{t-1}$ and $N_{O}$ refer to the numbers of polyps at times $t, t-1$ and 0 , respectively. The effect of temperature, food density and feeding frequency on the standardised daily growth rate $(X)$ was determined using three-way factorial ANOVA, and the effect of density on the daily growth rates was examined using regression techniques. Probability values for all tests were considered significant at a 0.05 level.

\section{Results}

Asexual reproduction was observed in all treatments. This took the form of: (i) lateral budding by means of stolons (ST); (ii) podocysts (POD); (iii) strobilation; and (iv) lateral budding (LB) (sensu Adler and Jarms 2009). Although 70\% of all polyps produced lateral stolons (Figure 1), fewer than $2 \%$ of these developed buds on the stolons. The number of stolons produced varied with food density and feeding frequency, but not temperature (Table 1).

Lateral budding was the most prevalent method of asexual reproduction by which new polyps were generated (Figure 1) and was first noticeable as a unilateral protrusion appearing at the junction of the polyp calyx and stalk. Soon thereafter, a stolon formed. The bud could be distinguished from the stolon on day 1, by the presence of a slight depression distally, surrounded by premature tentacles. Day 2 presented a bud with a defined mouth opening, and one or two well-developed tentacle primordia: the stolon had extended rapidly to attach to the Petri dish. From day 3 onwards, the bud was fully formed and able to feed. Daughter polyps detached themselves from the parent polyp by means of the new stolon, thereby moving away from the parent location. 
Ephyrae were produced by only two polyps during the course of the experiment: both at $12{ }^{\circ} \mathrm{C}$ and at low food densities (i.e. 30 Artemia nauplii $200 \mathrm{ml}^{-1}$, fed daily; 70 Artemia nauplii $200 \mathrm{ml}^{-1}$, fed every third day); the number of ephyral discs observed was eight and five, respectively. Podocysts were produced in low numbers at all temperatures, though more were produced at lower food densities (30 or 70 Artemia nauplii $200 \mathrm{ml}^{-1}$ ) than at higher ones (100 or 150 Artemia nauplii $200 \mathrm{ml}^{-1}$ ). No podocysts were produced by starved polyps, and no excystment was observed during the course of the experiment.

The results of the GLMM (Table 1) revealed that all the variables impacted asexual reproduction, and that greater polyp production was generally attained at higher food concentrations, increased feeding frequencies and increased temperatures (Figure 2). Warmer temperatures and higher food concentrations also tended to be associated with a slightly earlier start to polyp proliferation. The number of new polyps grew exponentially (Figure 2) after an initial lag period of 23 days.

Standardised daily growth rates $(X)$ varied between 1.012 and 1.063 polyps per polyp per day when fed daily, or between 1.002 and 1.027 when fed once every three days (Table 2). As noted by the results of the GLMM on polyp numbers, the results of the three-way factorial ANOVA reveal that the standardised daily growth rate $(X)$ was impacted by all three predictor variables (Table 3 ). The overall model was significant (adjusted $R^{2}=0.55, F=6.072, p<0.001$ ), though none of the predictors were, in any combination (Table 3). The relationship between time and standardised daily growth rate $(X)$ was positive and linear at lower temperatures, food densities and feeding frequencies, but approximately S-shaped at higher food densities and temperatures (data not shown). When all data were pooled, an exponential curve best fitted the relationship between polyp population size and standardised daily growth rate $(X)\left(R^{2}=0.86\right)$, which stabilised at between 1.11 and 1.13 polyps per polyp per day following an observed density of approximately 15 polyps per clone. This appears to represent the maximum standardised growth rate that could be observed in the experimental population (Figure 3a). The slight negative relationship between daily population growth rate $(r)$ and population density was not significant $\left(R^{2}=0.03\right)$ (Figure $\left.3 \mathrm{~b}\right)$. 


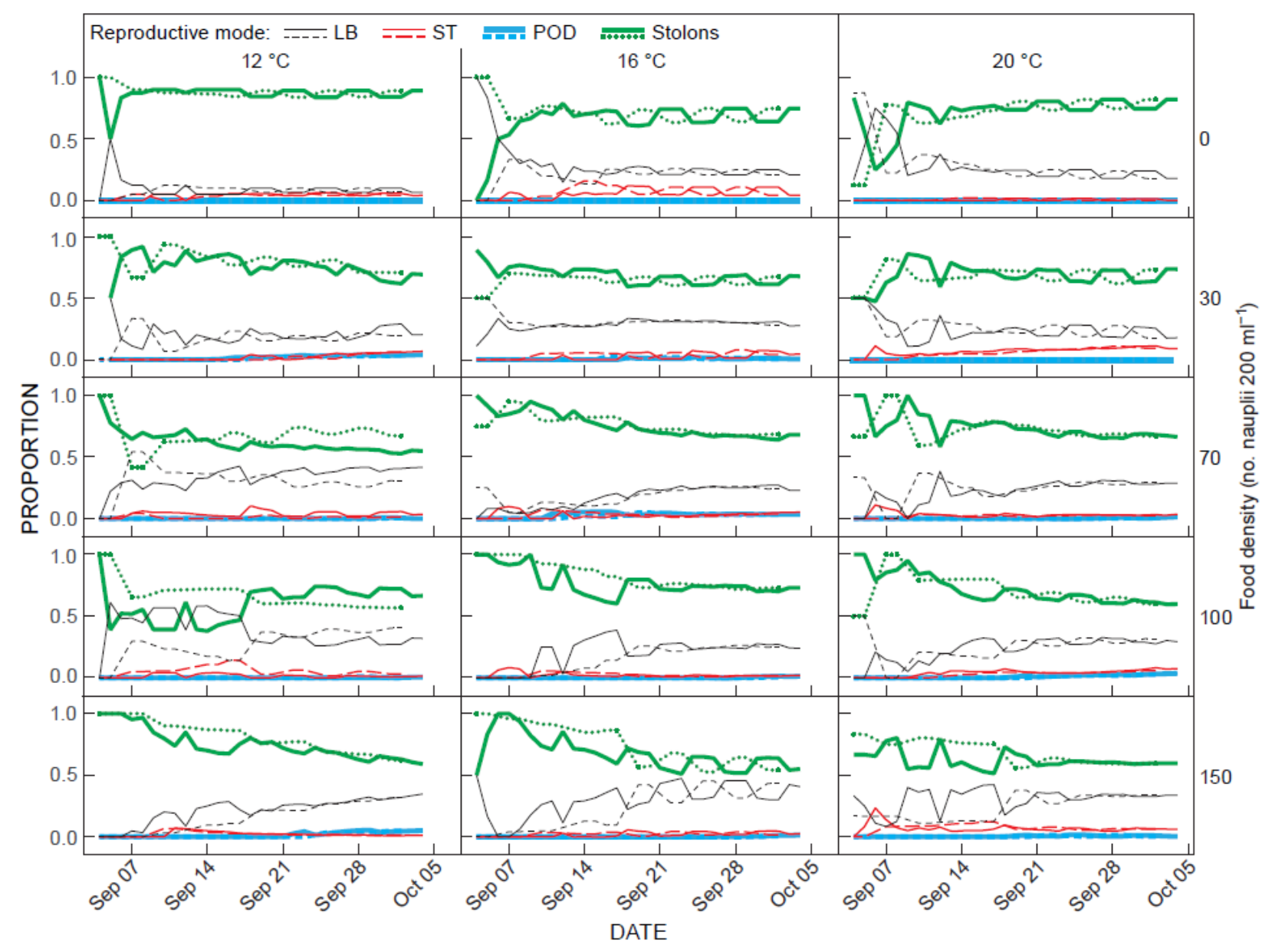

Figure 1: Changes in the proportional contribution of the different modes of asexual reproduction (i.e. typical lateral budding - LB, lateral buds by means of stolons - ST, and podocysts - POD) in comparison to stolon formation, as exhibited by polyps of Chrysaora fulgida through time in the different experimental treatments. Feeding frequency 1 (once daily) is indicated by solid lines, and feeding frequency 2 (once every third day) by broken lines

\section{Discussion}

The most frequently displayed method of asexual reproduction by polyps of Chrysaora fulgida was typical lateral budding (sensu Adler and Jarms 2009). This form of asexual reproduction is common in Scyphozoa, having been reported for, among other species, Sanderia malayensis, C. hysoscella (Chuin 1930), Aurelia aurita (Han and Uye 2010), A. coerulea and A. relicta (Hubot et al. 2017). Lateral budding by means of stolons has previously been reported for other members of the genus Chrysaora (see references in Adler and Jarms 2009), and Hubot et al. (2017) noted that it was more commonly employed by polyps of $A$. coerulea and A. relicta at a higher temperature (i.e. $21{ }^{\circ} \mathrm{C}$ ). While the polyps of C. fulgida observed here produced stolons, and some few of these stolons developed buds, the buds never developed into polyps themselves, and it appeared as though the stolons were used for stabilisation and movement. These observations are in contrast to those regarding many other Chrysaora species, which are known to favour lateral budding by means of stolons as a means of asexual reproduction (e.g. Condon et al. 2001; Adler and Jarms 2009), or, in the case of C. fuscescens, by podocysts (Widmer 2008b). Although 
podocysts were produced by some of the $C$. fulgida polyps under all experimental conditions when fed, in no instance did these excyst and develop into polyps. All of these results merely support the fact that scyphozoan scyphistomae display a variety of modes of asexual reproduction (Adler and Jarms 2009)

Table 1: Summary of results from the generalised linear mixed-effects model; $z$-values and $p$-levels are shown for all fixed variables. None of the interactions were significant, and are thus not included in the table

\begin{tabular}{|c|c|c|c|}
\hline Response variable & Fixed effects & Z-value & $p$-value \\
\hline \multirow{7}{*}{ Total no. of polyps produced } & Temperature & 2.981 & 0.003 \\
\hline & Frequency & -2.626 & 0.009 \\
\hline & Food density & -2.314 & 0.020 \\
\hline & Time & 7.313 & 0.001 \\
\hline & Temperature : Time & -2.532 & 0.011 \\
\hline & Frequency : Time & 2.098 & 0.036 \\
\hline & Food density : Time & 3.945 & 0.001 \\
\hline \multirow[t]{7}{*}{ Cumulative no. of stolons } & Temperature & 1.507 & 0.132 \\
\hline & Frequency & -1.920 & 0.054 \\
\hline & Food density & -8.372 & 0.001 \\
\hline & Time & 17.940 & 0.001 \\
\hline & Temperature : Time & -0.865 & 0.387 \\
\hline & Frequency : Time & 1.964 & 0.049 \\
\hline & Food density : Time & 10.223 & 0.001 \\
\hline \multirow[t]{7}{*}{ Cumulative no. of buds from stolons } & Temperature & -0.989 & 0.323 \\
\hline & Frequency & -0.197 & 0.844 \\
\hline & Food density & 0.623 & 0.533 \\
\hline & Time & 4.539 & 0.001 \\
\hline & Temperature : Time & 1.623 & 0.105 \\
\hline & Frequency : Time & 0.249 & 0.803 \\
\hline & Food density : Time & -0.112 & 0.910 \\
\hline \multirow[t]{7}{*}{ Cumulative no. of buds from polyps } & Temperature & 4.915 & 0.001 \\
\hline & Frequency & -4.503 & 0.001 \\
\hline & Food density & -12.502 & 0.001 \\
\hline & Time & 12.332 & 0.001 \\
\hline & Temperature : Time & -4.238 & 0.001 \\
\hline & Frequency : Time & 4.579 & 0.001 \\
\hline & Food density : Time & 14.763 & 0.001 \\
\hline \multirow[t]{7}{*}{ Cumulative no. of podocysts } & Temperature & 0.461 & 0.645 \\
\hline & Frequency & -1.995 & 0.001 \\
\hline & Food density & -4.340 & 0.001 \\
\hline & Time & 1.273 & 0.203 \\
\hline & Temperature : Time & -0.359 & 0.719 \\
\hline & Frequency : Time & 2.189 & 0.001 \\
\hline & Food density : Time & 4.811 & 0.001 \\
\hline
\end{tabular}

and our understanding of which method is employed by which species and under which set of circumstances is at present unclear, especially as it may vary with population 
density (Schiariti et al. 2015). We cannot comment on strobilation by C. fulgida in the laboratory at this stage, because the data collected here are scant, and the study was not designed to examine strobilation.

Temperature, food density and feeding frequency all affected the growth and asexual reproduction of polyps of $C$. fulgida. This is not new information per se, as a number of authors have shown that, as food availability and ambient water temperature increase, the number and asexual development of polyp clones (number of polyps and buds in the clonal colony) and individual polyps (number of buds per active polyp), increase significantly (e.g. Han and Uye 2010). Nevertheless, the standardised daily growth rates reported here for $C$. fulgida are among the highest recorded for polyps of any jellyfish species in culture. For example, the standardised growth rate of a polyp of $C$. fuscescens has been measured at 1.017 (Widmer et al. 2008b), whereas Purcell (2007) has shown that polyps of $A$. labiate have standardised growth rates of 1.011-1.016. Our data therefore suggest that polyp populations of $C$. fulgida can expand rapidly-even under cool temperatures and 'relatively low' food concentrations.

The lack of a significant relationship between daily population growth rate and population density suggests an absence of density-dependent controls on growth at the densities studied. This result contrasts with those of Melica et al. (2014) and Schiariti et al. (2015), who noted that increases in density led to reductions in growth rate. Indeed, the results of both those studies imply that polyp populations (in the laboratory) may be regulated around a carrying capacity, and Schiariti et al. (2015) intriguingly suggest that, at very high densities, polyps may switch their mode of asexual reproductive to facilitate emigration. Carrying capacities were not attained in the present study, which perhaps simply implies that the experiments were not conducted for long enough.

Caution should be exercised in extrapolating the present data to the field, because even the lowest prey density used here (30 Artemia nauplii $200 \mathrm{ml}^{-1}$ ) exceeds the highest recent in situ estimates off Walvis Bay (Verheye et al. 2016). 


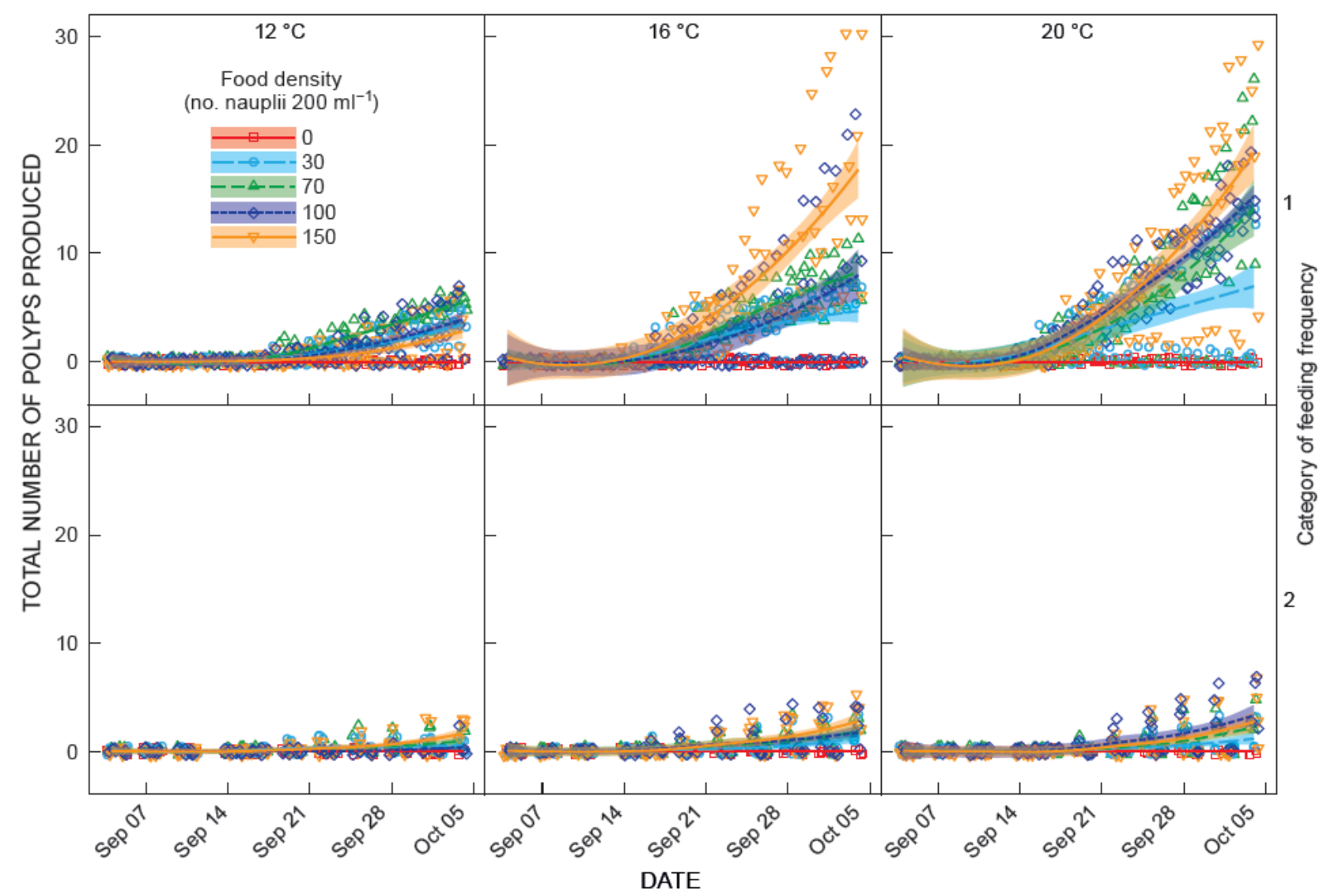

Figure 2: Cumulative number of polyps produced from parent polyps of Chrysaora fulgida reared under varying food densities, temperatures and feeding frequencies ( 1 = once daily; 2 = once every third day), across the four-week experimental period. Shaded areas around fitted lines indicate $95 \%$ confidence intervals

Table 2: Means (standard deviation) of the standardised daily population growth rates of Chrysaora fulgida polyps (polyps per polyp per day), calculated after 30 days in the laboratory, under different combinations of water temperature, food density (no. Artemia nauplii $200 \mathrm{ml}^{-1}$ ) and feeding frequency; in all instances, $n=4$

\begin{tabular}{|c|c|c|c|c|c|c|}
\hline \multirow{2}{*}{$\begin{array}{l}\text { Feeding } \\
\text { frequency }\end{array}$} & \multirow{2}{*}{$\begin{array}{c}\text { Temperature } \\
\left({ }^{\circ} \mathrm{C}\right)\end{array}$} & \multicolumn{5}{|c|}{ Food density } \\
\hline & & 0 & 30 & 70 & 100 & 150 \\
\hline \multirow[t]{3}{*}{ Once daily } & 12 & $1(0)$ & $1.019(0.025)$ & $1.03(0.0316)$ & $1.018(0.0265)$ & $1.012(0.0229)$ \\
\hline & 16 & $1(0)$ & $1.033(0.0396)$ & $1.042(0.0412)$ & $1.026(0.0428)$ & $1.056(0.0511)$ \\
\hline & 18 & $1(0)$ & $1.042(0.0487)$ & $1.046(0.0523)$ & $1.063(0.0496)$ & $1.056(0.0531)$ \\
\hline \multirow{3}{*}{$\begin{array}{l}\text { Once every } \\
\text { third day }\end{array}$} & 12 & $1(0)$ & $1.013(0.0165)$ & $1.011(0.0179)$ & $1.002(0.0072)$ & $1.014(0.0199)$ \\
\hline & 16 & $1(0)$ & $1.012(0.0205)$ & $1.022(0.0231)$ & $1.021(0.0285)$ & $1.025(0.0281)$ \\
\hline & 18 & $1(0)$ & $1.011(0.0203)$ & $1.017(0.0228)$ & $1.027(0.0311)$ & $1.018(0.0288)$ \\
\hline
\end{tabular}

Nonetheless, polyps of Chrysaora fulgida clearly have a capacity to respond even to what are likely to be considered ad libitum concentrations of prey. Type-II feeding responses are typically exponential at food concentrations above a baseline threshold (Begon et al. 2006) and flatten towards satiation.

Given the response of scyphistomae of Chrysaora fulgida to food availability and water temperature, both of which have increased off parts of Namibia in recent decades (Salvanes et al. 2015; Verheye et al. 2016), it is not unlikely that polyp populations have expanded. Beyond the expansion that will have occurred following the increase in medusa 
population sizes subsequent to the demise of pelagic fish populations (Roux et al. 2013) and the likely increase in planulae recruitment (see also Gibbons et al. 2016), it is clear that renewed efforts are merited to locate the polyp beds of $C$. fulgida off Namibia so that direct measurements (cf. Di Camillo et al. 2010) can be made on this 'hidden' stage in the jellyfish's life cycle.

Table 3: Univariate tests of significance from a three-way factorial ANOVA to illustrate the main effects and the interactions of water temperature, feeding frequency and food density on the standardised growth rates $(X)$ of Chrysaora fulgida polyps, calculated at $t=30$

\begin{tabular}{|c|c|c|c|c|c|}
\hline & SS & df & MS & $F$ & $p$-value \\
\hline Intercept & 129.922 & 1 & 129.922 & 221575.3 & 0.000 \\
\hline Temperature & 0.009 & 2 & 0.005 & 7.8 & 0.001 \\
\hline Feeding frequency & 0.019 & 1 & 0.019 & 31.6 & 0.000 \\
\hline Food density & 0.057 & 4 & 0.014 & 24.3 & 0.000 \\
\hline Temperature : Feeding frequency & 0.001 & 2 & 0.000 & 0.5 & 0.629 \\
\hline Temperature : Food density & 0.009 & 8 & 0.001 & 1.9 & 0.067 \\
\hline Feeding frequency : Food density & 0.005 & 4 & 0.001 & 2.1 & 0.093 \\
\hline Temperature : Feeding frequency : Food density & 0.004 & 8 & 0.001 & 0.9 & 0.527 \\
\hline Error & 0.053 & 90 & 0.001 & & \\
\hline
\end{tabular}

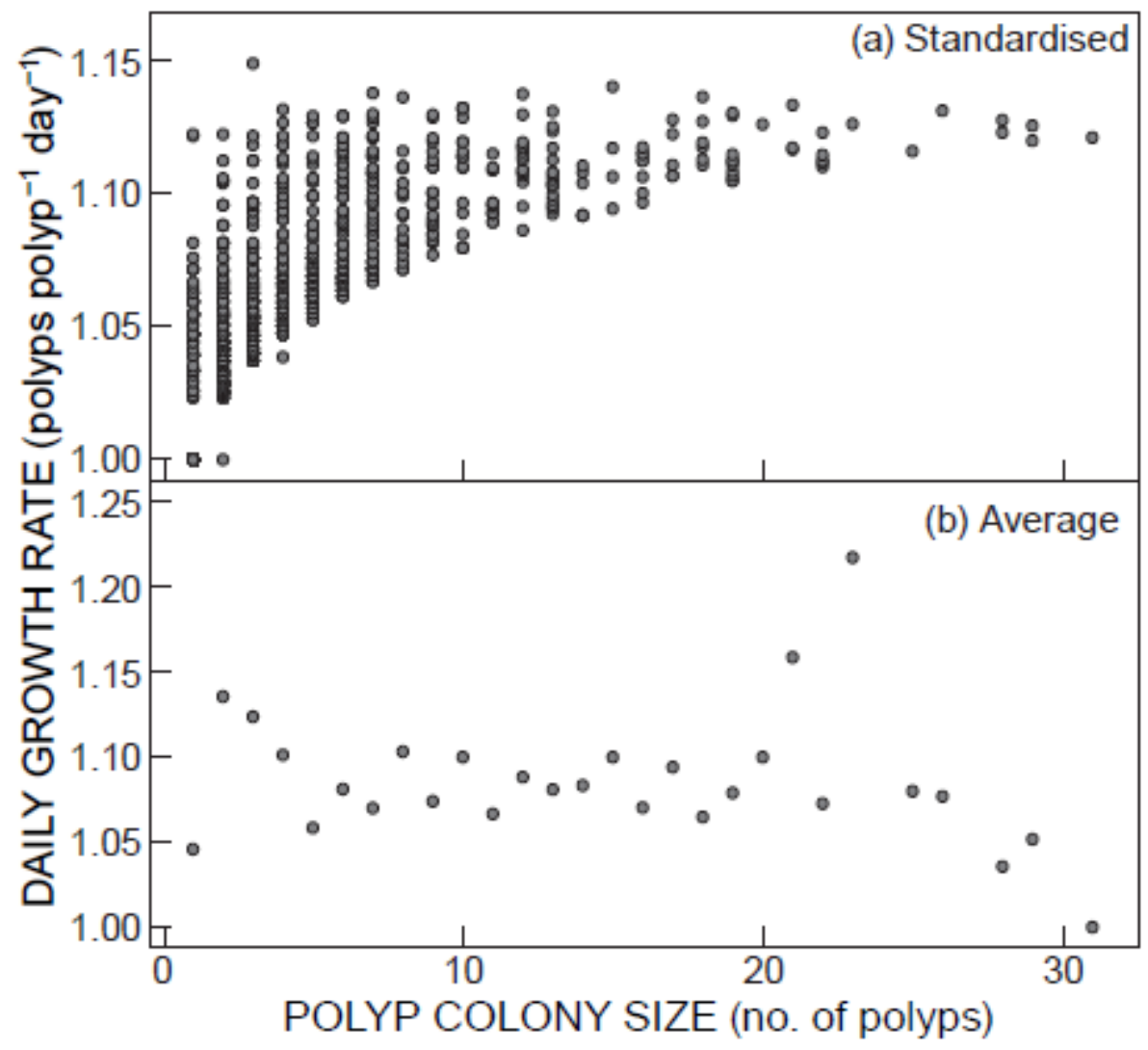

Figure 3: The effects of Chrysaora fulgida polyp colony size on (a) standardised daily growth rate $(X)$, and (b) average daily growth rate $(r)$ 
Acknowledgements - We would like to thank Deborah Robertson-Andersson (currently University of KwaZulu-Natal, South Africa) for initially succeeding to establish a laboratory culture of Chrysaora fulgida, and we acknowledge Krish Lewis (Two Oceans Aquarium) for providing ongoing support. We are grateful to the National Research Foundation of South Africa for funding. 


\section{References}

Alder L, Jarms G. 2009. New insights into reproductive traits of scyphozoans: special methods of propagation in Sanderia malayensis Goette, 1886 (Pelagiidae, Semaeostomeae) enable establishing a new classification of asexual reproduction in the Class Scyphozoa. Marine Biology 156: 1411-1420.

Bakun A, Weeks SJ. 2006. Adverse feedback sequences in exploited marine systems: Are deliberate interruptive actions warranted? Fish and Fisheries 7: 316-333.

Begon M, Townsend CR, Harper JL. 2006. Ecology: from individuals to ecosystems (4th edn). Malden, Massachusetts: Blackwell.

Brotz L, Cheung WWL, Kleisner K, Pakhomov E, Pauly D. 2012. Increasing jellyfish populations: trends in large marine ecosystems. Hydrobiologia 690: 3-20.

Chuin TT. 1930. Le cycle évolutif du scyphistome de Chrysaora. Travaux de la Station Biologique de Roscoff 8: 1-174.

Condon P, Decker MB, Purcell JE. 2001. Effects of low dissolved oxygen on survival and asexual reproduction of scyphozoan polyps (Chrysaora quinquecirrha). Hydrobiologia 451: 89-95.

Condon RH, Duarte CM, Pitt KA, Robinson KL, Lucas CH, Sutherland KR, Mianzan HW et al. 2013. Recurrent jellyfish blooms are a consequence of global oscillations. Proceedings of the National Academy of Sciences of the United States of America 110: 1000-1005.

Di Camillo CG, Betti F, Bo M, Martinelli M, Puce S, Bavestrello G. 2010. Contribution to the understanding of seasonal cycle of Aurelia aurita (Cnidaria: Scyphozoa) scyphopolyps in the northern Adriatic Sea. Journal of the Marine Biological Association of the United Kingdom 90: 1105-1110.

Flynn BA, Richardson AJ, Brierley AS, Boyer DC, Axelsen BE, Scott L et al. 2012. Temporal and spatial patterns in the abundance of jellyfish in the northern Benguela upwelling ecosystem and their link to thwarted pelagic fishery recovery. African Journal of Marine Science 34: 131-146.

Gibbons MJ, Richardson A. 2013. Beyond the jellyfish joyride and global oscillations: advancing jellyfish research. Journal of Plankton Research 35: 929-938.

Gibbons MJ, Boero F, Brotz L. 2016. We should not assume that fishing jellyfish will solve our jellyfish problem. ICES Journal of Marine Science 73: 1012-1018.

Han C, Uye S. 2010. Combined effects of food supply and temperature on asexual reproduction and somatic growth of polyps of the common jellyfish Aurelia aurita s.l. Plankton and Benthos Research 5: 98-105.

Hansson LJ. 1997. Effect of temperature on growth rate of Aurelia aurita (Cnidaria, Scyphozoa) from Gullmarsfjorden, Sweden. Marine Ecology Progress Series 161: $145^{-153 .}$

Hubot N, Lucas CH, Piraino S. 2017. Environmental control of asexual reproduction and somatic growth of Aurelia spp. (Cnidaria, Scyphozoa) polyps from the Adriatic Sea. PLOS ONE 12: 1-16.

Lucas CH, Graham WM, Widmer C. 2012. Jellyfish life histories: role of polyps in forming and maintaining scyphomedusa populations. Advances in Marine Biology 63:134184 . 
Lynam CP, Gibbons MJ, Axelsen BE, Sparks CAJ, Coetzee J, Heywood BG, Brierley AS. 2006. Jellyfish overtake fish in a heavily fished ecosystem. Current Biology 16: 492-493.

Melica V, Invernizzi S, Caristi G. 2014. Logistic density-dependent growth of an Aurelia aurita polyps population. Ecological Modelling 291: 1-5.

Olesen NJ, Purcell JE, Stoecker DK. 1996. Feeding and growth by ephyrae of scyphomedusae Chrysaora quinquecirrha. Marine Ecology Progress Series 137: 149159.

Purcell JE. 2007. Environmental effects on asexual reproduction rates of the scyphozoan Aurelia labiata. Marine Ecology Progress Series 348: 183-196.

Purcell JE, Uye S, Lo T. 2007. Anthropogenic causes of jellyfish blooms and their direct consequences for humans: a review. Marine Ecology Progress Series 350: 153-174.

Richardson AJ, Pauly D, Gibbons MJ. 2012. Degraded ecosystems: keep jellyfish numbers in check. Nature 482: 20-21. Roux J, van der Lingen CD, Gibbons MJ, Moroff NE, Shannon LJ,

Smith AD, Cury PM. 2013. Jellyfication of marine ecosystems as a likely consequence of overfishing small pelagic fishes: lessons from the Benguela. Bulletin of Marine Science 89: 249-284.

Salvanes AGV, Bartholomae C, Yemane D, Gibbons MJ, Kainge P, Krakstad J-O et al. 2015. Spatial dynamics of the bearded goby and its key fish predators off Namibia vary with climate and oxygen availability. Fisheries Oceanography 24: 88-101.

Schiariti A, Morandini AC, Jarms G, von Glehn Paes R, Franke S, Mianzan H. 2014. Asexual reproduction strategies in blooming potential in Scyphozoa. Marine Ecology Progress Series 510: 241-253.

Schiariti A, Melica V, Kogovšek T, Malej A. 2015. Density-dependent effects control the reproductive strategy and population growth of Aurelia aurita s.l. scyphistomae. Marine Biology 162: 1665-1672.

Venter GE. 1988. Occurrence of jellyfish on the west coast off South West Africa/Namibia. In: MacDonald IAW, Crawford RJM (eds), Long-term data series relating to southern Africa's renewable natural resources. South African National Science Programmes Report No. 157. Pretoria, South Africa: Foundation for Research Development, Council for Scientific and Industrial Research. pp 56-61.

Verheye HM, Lamont T, Huggett JA, Kreiner A, Hampton I. 2016. Plankton productivity of the Benguela Current Large Marine Ecosystem (BCLME). Environmental Development 17: 75-92.

Widmer CL. 2005. Effects of temperature on growth of north-east Pacific moon jellyfish ephyrae, Aurelia labiata (Cnidaria: Scyphozoa). Journal of the Marine Biological Association of the United Kingdom 85: 569-573.

Widmer CL. 2008a. How to keep jellyfish in aquariums: an introductory guide for maintaining healthy jellies. Tucson, Arizona: Wheatmark.

Widmer CL. 2008b. Life cycle of Chrysaora fuscescens (Cnidaria: Scyphozoa) and a key to sympatric ephyrae. Pacific Science 62: 71-82. 